\title{
TRANSIENT SIMULATION OF IMPULSE WIND EFFECT ON A TALL SHIPYARD FRAME STRUCTURE
}

\author{
Goran Radoičić* \\ Public Utility Company Mediana, Niš, Serbia \\ Miomir Jovanović \\ University of Niš, Faculty of Mechanical Engineering, Niš, Serbia
}

This paper presents the importance of a dynamically checked design of the shipbuilding portal rotating crane geometry regarding wind load. The dynamic character of wind load is mathematically introduced by a harmonic function of excitation and logarithmic wind speed profile. Structural analysis on the nonlinear model of the crane is carried out using the finite element method. The dissipation function is described by using an adequate model of structural damping. Combining the tracking and transformation methods, the eigenvalues of the FEM model of the observed structure were extracted. This research provides a faithful mechanical model of the crane for transient analysis in which structural elasticity is verified on the real structure. Through several case studies, the paper indicates a greater danger of a multi-wave wind gust at the steady state of wind speeds statistically recorded in relation to a single-wave wind gust at the extremely recorded speed. Based on the conducted dynamic simulations of wind action a new design criterion is suggested - the conditional quotient of structural geometry.

Key words: Dynamic response, Engineering design, Modelling, Simulation, Wind load

\section{IN BRIEF ABOUT WIND}

The impact of hurricane on high buildings or cranes which do not have the survival mode in the rest position, can directly endanger their integrity and stability. One such characteristic structure is a tall Shipyard level-luffing Crane (SC) with a horse-head section that is constantly faced with complex environmental load conditions. This crane has an expressed risk of collapse due to its broad vertical flat area exposed to the load of changeable wind and a tall structure of height $\mathrm{H}$ in relation to the portal basis $\mathrm{b} \times \mathrm{d}$ that is about ten times smaller than the height (this refers to one of the dimensions - dim. b, in the direction of the wind).

The gusts of strong wind frequently lead to galloping oscillations, resonance and collapse of structures. Apart from crane height, orographic factors have a significant influence on a structure which multiplies the wind effect. On the basis of the research [01] a reference can be made to a number of recent breakdown events of cranes and other big construction facilities over the world. Extreme gusts of strong wind are rare occurrences but should still be taken into consideration in the design of tall cranes and other shipyard and marine structures. One should strive towards better geometric criteria in the design of level-luffing cranes that would lead to a more efficient response of the support structure on extreme recorded environmental loads, especially to unfavourable combinations of natural phenomena at which their collapses occur, [02], [03].

Wind is observed as a phenomenon with a constant effect because of its large period of oscillation, i.e. small frequency, so that it is modelled as a constant load in civil-engineering calculation. However, this constant wind effect on structure can cause, and it often does cause, the resonant vibrations as the consequence of the interaction between the structure and wind flow. There are two key reasons for it: underpressure due to airflow turbulence in certain zones around construction, and so-called "flutter" or "follower force" as a nonlinear load that depends on structural deformation (example: airplane wing). Thus, one can conclude that the wind load is variable with the same eigenfrequency of the structure which leads to resonance (example: Tacoma Narrow Bridge, [01]). 
The wind force is decomposed into two components - the horizontal and the vertical. The horizontal component of the force is induced by the vortexing of air in the vicinity of the body or crane support structure. This force component is particularly expressed for bodies without the aerodynamic profile. Contrary to that, the vertical component of the wind load occurs due to the air flow with the relative speed vr. This force component acts on the vertical surface of the crane at an angle of $(90-a)^{\circ}$. The vertical force component leads to the galloping vibration effect on the observed machine. This aerodynamic vertical force component can be labelled as Fav. It also has two components, and these are: Fd - the component in the direction of velocity $\mathrm{vr}$, named the drag-force, and $\mathrm{FI}$ - the component that is perpendicular to the direction $\mathrm{vr}$, named the lift force, [03]. In this research, two important assumptions are adopted: the vertical force $\mathrm{Fa}^{\mathrm{v}}$ has a harmonic nature and the incidence angle is $a=0^{\circ}$.

The wind load model requires the modelling of interactive effect between the air flow and structure, as well as a nonlinear formulation with a very small time step ("follower forces" are not conservative forces). A comprehensive (better) method of modelling should harmonize a wind flow model defined by the Euler formulation and model of support structure described by the Lagrangian formulation. Therefore, the oscillation period of wind in this research is assumed on an approximate three-minute duration of sustainable wind flow at the reference speed, that also represents the oscillation period of the structure (resonance effect).

\section{RELEVANT METEOROLOGICAL REFERENCES}

The observation of wind sustainability varies by the region of tropical cyclones so that the oneminute regime is characteristic for North Atlantic Ocean and Eastern Pacific Ocean, and the tenminute regime for South-West Indian Ocean and Australian Region [04] - Table 1.

Table 1: Some of the most intense cyclones in the last few years [04]

\begin{tabular}{|c|c|c|c|}
\hline \multicolumn{2}{|c|}{ North Atlantic Ocean } & \multicolumn{2}{|c|}{ Eastern Pacific Ocean } \\
\hline Wilma 2005 & $295 \mathrm{~km} / \mathrm{h}$ & Patricia 2015 & $325 \mathrm{~km} / \mathrm{h}$ \\
\hline \multicolumn{2}{|l|}{ South-West Indian } & \multicolumn{2}{|l|}{$\begin{array}{l}\text { Australian Region } \\
\end{array}$} \\
\hline Eunice 2014-15 & $240 \mathrm{~km} / \mathrm{h}$ & Monica 2005-06 & $250 \mathrm{~km} / \mathrm{h}$ \\
\hline
\end{tabular}

The measured maximal wind speeds in Croatia [05] confirm a known fact that we can clearly distinguish the climate wind in continental areas in relation to coastal areas and islands. However, the specific positions of bridges: Pag, Krk, and Maslenica, in relation to the surrounding orography, cause higher ten-minute wind speeds of even above $40 \mathrm{~m} / \mathrm{s}$ and maximal wind gusts of above $60 \mathrm{~m} / \mathrm{s}$. In the calculations of the impact effect of wind on the chosen crane, two quantities of the reference wind speed are taken into account as follows: $35 \mathrm{~m} / \mathrm{s}$ and $45 \mathrm{~m} / \mathrm{s}$, because such and even higher impact speeds were statistically recorded on the Balkan Peninsula.

\section{THEORETICAL FRAMEWORK}

The exploration of transient responses of a discrete finite element system, such as the FE model of a shipyard level-luffing crane, is based on the formulation in Eq. (1).

$$
[\mathrm{M}]^{\mathrm{t}}\{\ddot{\mathrm{u}}\}+{ }^{\mathrm{t}}[\mathrm{C}]^{\mathrm{t}}\{\dot{\mathrm{u}}\}={ }^{\mathrm{t}}\left\{\mathrm{f}_{\mathrm{ext}}\right\}-{ }^{\mathrm{t}}\left\{\mathrm{f}_{\mathrm{int}}\right\}
$$

Where: $[\mathrm{M}]$ is the inertial matrix, $[\mathrm{C}]$ is the damping matrix, $\{f e x t\}$ is the vector of external forces, $\{$ fint $\}$ is the vector of internal forces, $\{\dot{\mathrm{u}}\}$ is the generalized velocity vector, $\{\ddot{\mathrm{u}}\}$ is the generalized acceleration vector, $t$ is the moment in time in which one of the sizes is observed.

Geometric nonlinear structural analysis requires the calculation of stress $\{\sigma\}$ in the current structural configuration, and the integration of those stresses in the current structural continuum $t_{v}$, with the aim of obtaining internal structural forces. Therefore, it can be written as:

$$
{ }^{\mathrm{t}}\left\{\mathrm{f}_{\text {int }}\right\}=\int_{{ }_{\mathrm{t}} \mathrm{t}}^{\mathrm{t}}[\mathrm{B}]^{\mathrm{t}}\{\sigma\} \mathrm{d}^{\mathrm{t}} \mathrm{V}
$$

where $[B]$ is the matrix of deformation-displacement (defining the linear members of the deformation field) of the FE model. The time integration method was chosen for the following reason. In the research, the Newmark time integration was used as an implicit integration method whose a time step was $0.001 \mathrm{~s}$. The decision was taken 
on the basis of the material of the considered structure (steel), excitation force and the range of oscillation. The dynamic balance of the geometrically nonlinear system from Eq. (1) could still be developed for time $t+\Delta t$ as:

$$
\begin{aligned}
& {[\mathrm{M}]^{\mathrm{t}+\Delta \mathrm{t}}\{\ddot{\mathrm{u}}\}^{(\mathrm{k})}+{ }^{\mathrm{t}+\Delta \mathrm{t}}[\mathrm{C}]^{\mathrm{t}+\Delta \mathrm{t}}\{\dot{\mathrm{u}}\}^{(\mathrm{k})}+} \\
& +{ }^{\mathrm{t}+\Delta \mathrm{t}}\left[\mathrm{K}_{\mathrm{T}}\right]^{\mathrm{t}+\Delta \mathrm{t}}\{\Delta \mathrm{u}\}^{(\mathrm{k})}={ }^{\mathrm{t}+\Delta \mathrm{t}}\left\{\mathrm{f}_{\text {ext }}\right\}^{\mathrm{t}+\Delta \mathrm{t}}\left\{\mathrm{f}_{\text {int }}\right\}^{(\mathrm{k}-1)}
\end{aligned}
$$

where: $[\mathrm{KT}]$ is the tangential stiffness matrix, $\Delta$ is the increment of a size, $k$ is the iteration. The matrix [KT] allows for the assessment of the elastic forces along with the increase in displacement at time $\mathrm{t}+\Delta \mathrm{t}$. The matrix [KT] is calculated according to:

$$
\begin{aligned}
& { }^{\mathrm{t}}\left[\mathrm{K}_{\mathrm{T}}\right]={ }^{\mathrm{t}}\left[\mathrm{K}_{\mathrm{L}}\right]+{ }^{\mathrm{t}}\left[\mathrm{K}_{\sigma}\right]= \\
& =\int_{\mathrm{t}_{\mathrm{V}}}{ }_{\mathrm{t}}^{\mathrm{t}}[\mathrm{B}]^{\mathrm{T}}[\mathrm{H}]^{\mathrm{t}}[\mathrm{B}] \mathrm{d}^{\mathrm{t}} \mathrm{V}+ \\
& \left.+\int_{\mathrm{t}_{\mathrm{V}}}{ }^{\mathrm{t}}\left[\mathrm{B}_{\mathrm{NL}}\right]^{\mathrm{T}}{ }^{\mathrm{t}}[\sigma]\right]^{\mathrm{t}}\left[\mathrm{B}_{\mathrm{NL}}\right] \mathrm{d}^{\mathrm{t}} \mathrm{V}
\end{aligned}
$$

where all quantities of the current structure are given in time $t$, as follows: ${ }^{[}[\mathrm{KL}]$ is the linear stiffness matrix, $[\mathrm{K} \sigma]$ is the geometric stiffness matrix, $[\mathrm{H}]$ is the Hooke's matrix, $[\mathrm{BNL}]$ is the matrix that yields the nonlinear part of the strains, and $[\sigma]$ is the stress state given in the matrix form.

\section{MODELLING OF A CRANE FRAME STRUCTURE}

For the purpose of transient simulation used to determine the behaviour of a high frame structure, a model of SC was designed with 225 finite elements and 135 nodes with 810 degrees of freedom. The model accurately represents a real existing structure (Figure 1). On the basis of the experimental investigations of dynamics of frame structures [06] and [07], the authors experimentally determined the safe coefficient of structural damping. This coefficient $(G)$ takes a value between 0.05 and 0.06 for tall cranes and similar machines. The MSC NASTRAN software was applied for structural modelling as well as geometrically nonlinear dynamic analysis of the designed model.

A new model of stiffness was experimentally proven (verified) on a real structure - the levelluffing crane (SC) in the Pula shipyard (Croatia), [08]. The max. height of SC is $67 \mathrm{~m}$, the max. reach is $40 \mathrm{~m}$, the dimensions of the portal basis are $b 1 \times d 1=6 \times 8 \mathrm{~m}$, the mass of the crane in total is 400 tons. The level-luffing system has a four- bar mechanism form with articulated connections between elements and rocker. The payload of the crane is $25 / 15 / 5$ tones to reach of $27 / 37 / 40$ $\mathrm{m}$, respectively. The central mast has the height of $30 \mathrm{~m}$. The mechanisms for movement are set within a rotating platform on the mast. A frame pylon structure is set above the mast and platform. The basic members of the level-luffing mechanism on the pylon are shown in Figure 1 (rod, boom, rocker). The drive mechanism for level-luffing has a spindle which acts on the basic boom. The boom system is balanced by using a structure in the form of a four-bar mechanism - an arm and a balancer with a counter-weight of $21 \mathrm{t}$ in mass. The overall rotating crane structure is equilibrated with a weight of 100 tones that is set on the platform.

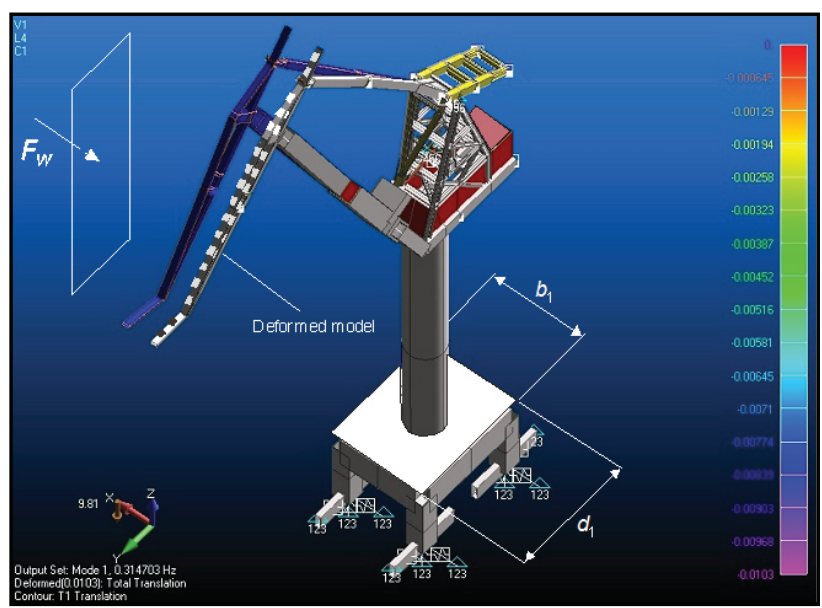

Figure 1: The first mode shape (eigenfrequency $w_{1}=0.3147 \mathrm{~Hz}$ ) of the shipbuilding crane

The elasticity of the developed finite element model of SC was verified by using the experimental results from the examination in the Pula shipyard. On that occasion the elasticity of the top of the jib, that is, the path of the rocker top was determined by optical levelling method. In this manner, the quality of modelling was checked. The results of experimental investigation are given in Fig. 2 and they show their analytical, numerical and experimental stacking.

In Figure 2, the dotted symbols of rectangular shape point to the measured values during the operation of the crane with a load. This experiment was carried out using an optical method. At the same figure, the black full curve shows a numerical envelope of the rocker top translations under the load of 12 tons in mass, calculated using the finite element analysis. The slightly brighter full curve gives us the theoretical trajectory of the rigid body mechanism i.e. starting positions 
of the top of the crane rocker. The experimental and numerical results of the rocker top deflection differ by $10 \%$ maximally throughout the full range of level-luffing, [09]. These deviations are mainly nonlinear in nature. They are caused by the rheological changes in the geometry of the track on the sea shore as well as manufacturing errors in making large-scale members of the crane steel structure.

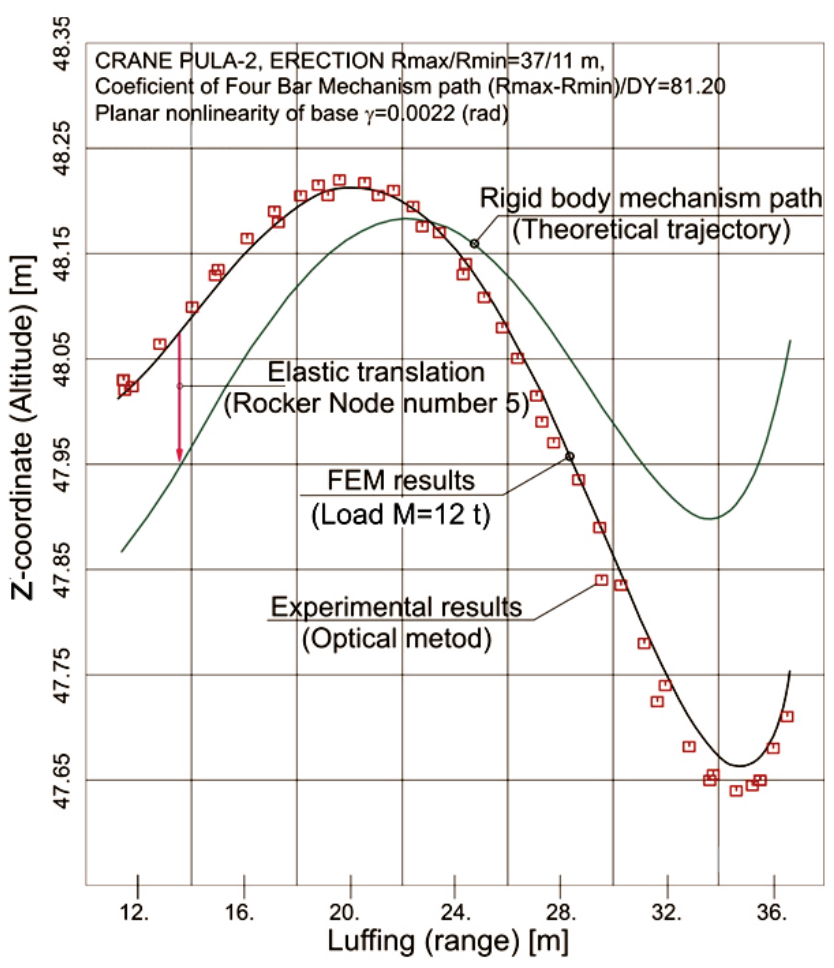

Figure 2: A verification for the experimental and theoretical elastic characteristics [09]

\section{DEVELOPMENT OF A WIND LOAD MODEL}

To analyse the behaviour of a high crane structure under the influence of strong wind, the authors selected a level-luffing crane at the shipyard UIjanik in Pula which is constantly exposed to the effects of air without its opportunity for self-protection i.e. switching to a safe-position. This shipyard crane has a multi-body structure. It contains several sub-structures such as: pedestal, tower, rotating platform, control cabin, counter-weight, pylon, boom (jib), rod, level-luffing mechanism and rocker. When creating models, most of the sub-structures can be modelled using frame and beam type of elements. The aforementioned element types can be considered sufficiently aerodynamic so as to approximately neglect the influence of the aerodynamic force due to swirling, thus it will not be taken into consideration in the direct transient analysis. Only the aerodynamic force $\mathrm{F}_{\mathrm{av}}$ is taken as a time-variable exter- nal load with a harmonic nature caused by wind gusts under the angle of incidence a compared to the normal of exposed (vertical) crane area. The wind force, in this research, was calculated in two ways, first as a static force in order to define the boundary conditions of static stability, and then as a dynamic perturbance force under the wind gusts to define the dynamic reserve of the crane structure.

The force of the wind which acts on the exposed surfaces of the crane in their gravity centres, varies with the height of the crane whose maximum value is 67 meters from the ground. In the direct calculation procedure, the whole structure of the crane is divided into seven parts - individual areas $A i$ where $i=1 \div 7$ indicates the serial number of surface (Figure 3). Because all surfaces are placed vertically, the same angle of incidence may be adopted and that as $a=0^{\circ}$ for each of the individual forces of wind Fi (It means: the force acts normally on the surface). When dimensioning the support structure of the crane, the force of wind pressure on the structural members is considered as a steady load.

Figure 3 and Table 2 show the heights $\mathrm{Zi}$ of the gravity centres $\mathrm{Ti}$ for each of the elementary surfaces Ai. Table 2 provides the descriptions and shape coefficients Cs for all used element shapes. The individual force of wind $\mathrm{Fw}(\mathrm{i})$ from Eq. (5) describes a steady state of the wind on an elementary surface Ai of the structure, taking into account the standards [10], [11] and [12] as well as research [13].

$\mathrm{F}_{\mathrm{W}}(\mathrm{i})=\frac{1}{2} \rho_{\mathrm{a}} \mathrm{C}_{\mathrm{s}}(\mathrm{i}) \mathrm{A}_{\mathrm{i}} \mathrm{v}^{2}(\mathrm{z}) \cos \alpha \quad[\mathrm{N}]$

Where: $R_{a}=1.225 \mathrm{~kg} / \mathrm{m}^{3}$ is the air density for dry air at the temperature of $15^{\circ} \mathrm{C}$; $\mathrm{Cs}$ is the shape coefficient (taken according to the until recently valid standard SRPS U.C7.113); $\mathrm{Ai}\left[\mathrm{m}^{2}\right]$ is the exposed surface of the each observed structural element (elementary surface at height zi); $\mathrm{v}=\mathrm{U}(\mathrm{z})[\mathrm{m} / \mathrm{s}]$ is the wind speed at each observed height $z$, taking into account the geographic terrain roughness $z_{0}$; $a=0^{0}$ is the angle between the direction of the wind effect and the normal to the surface of the observed element of the structure (if the wind acts perpendicularly on the surface then $a=0^{\circ}$, cosa $=1$ ).

To calculate the vertical wind profile at a given height $z$, the logarithmic profile model, in accordance with the standard [14] and conditions of a 10-minute speed averaging $\mathrm{U}(\mathrm{Href})$ at a refer- 
ence height of Href=10 m used here. The logarithmic wind speed profile is defined as:

$$
\mathrm{U}(\mathrm{z})=\mathrm{U}\left(\mathrm{H}_{\mathrm{ref}}\right)\left(1+\frac{1}{\mathrm{k}_{\mathrm{a}}} \sqrt{\kappa} \ln \frac{\mathrm{z}}{\mathrm{H}_{\mathrm{ref}}}\right)
$$

Where $U(z)$ is the current wind speed at the height $z$ and $U(H r e f)$ iz the averaged wind speed at the reference height Href=10 $\mathrm{m}$ at the exposure of $\mathrm{T}=10 \mathrm{~min}$, i.e.:

$$
\mathrm{U}\left(\mathrm{H}_{\mathrm{ref}}\right)=\left\{\begin{array}{c}
\mathrm{U}_{1}(10)=v_{1, \text { ref }}=35 \mathrm{~m} / \mathrm{s} \\
\mathrm{U}_{2}(10)=v_{2, \text { ref }}=45 \mathrm{~m} / \mathrm{s}
\end{array}\right.
$$

As well as: Href=10 $\mathrm{m}$ - the reference height; $k a=0.4$ - the von Kármán constant; $z_{0}=0.001$ $0.01 \mathrm{~m}$, adopted $\mathrm{z}_{0}=0.01 \mathrm{~m}$ - the terrain roughness parameter for coastal areas with onshore
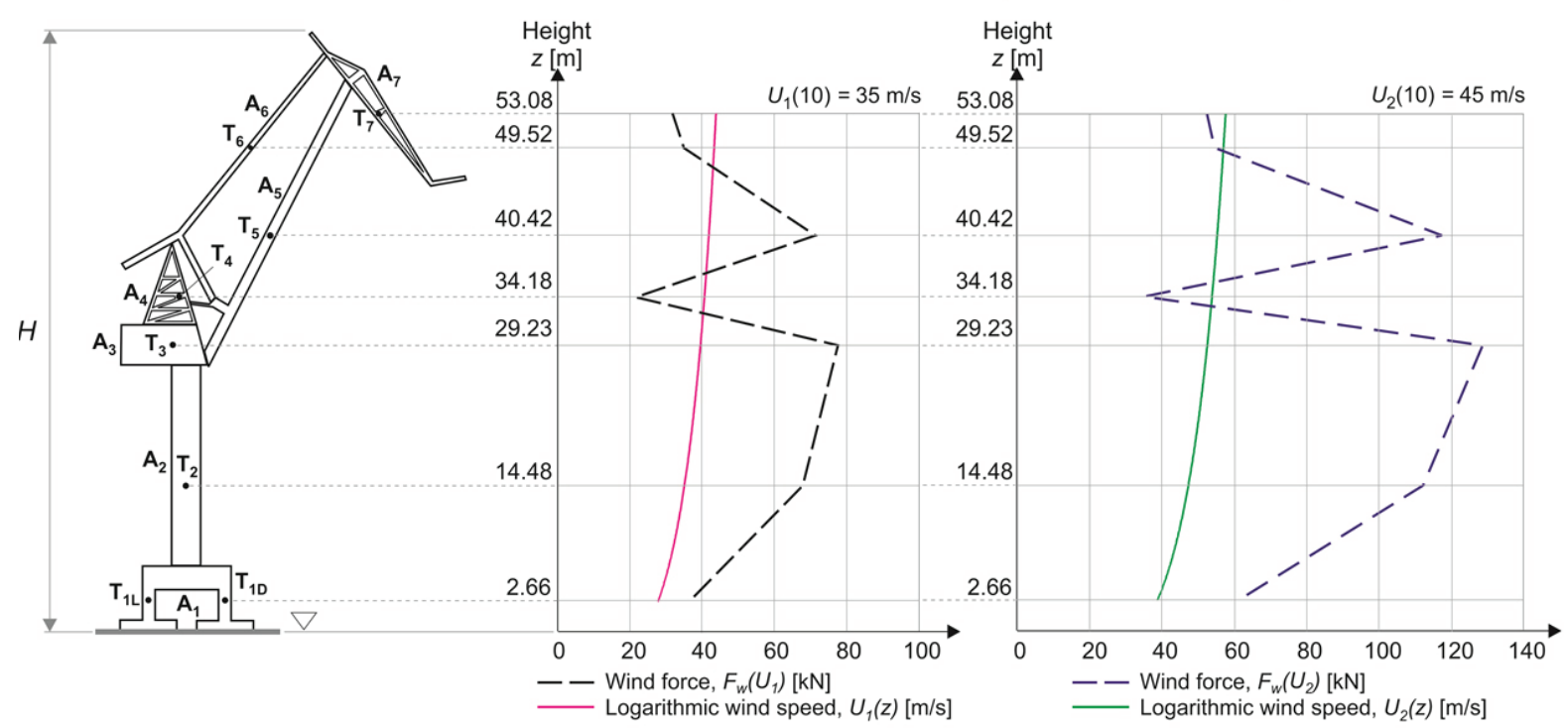

Figure 3: Crane model with elementary surfaces, wind speed (Eq.(8)) and wind force (Eq.(5)) respectively from left to right, depending on the height of surface gravity centres $z$ and reference speed U(Href)

Table 2: Calculation of the wind speed $U(\mathrm{z})$ and wind force $F w(U)$

\begin{tabular}{||c||c||c||c||c||c||c||c||c||}
\hline \hline & $\begin{array}{c}\text { Exposed } \\
\text { surface Ai } \\
{\left[\mathrm{m}^{2}\right]}\end{array}$ & $\begin{array}{c}\text { Height } \\
\text { zi [m] }\end{array}$ & $\begin{array}{c}\text { Element shape } \\
\text { (for each of Ai) }\end{array}$ & $\begin{array}{c}\text { Shape } \\
\text { coef. } \\
\text { Cs [-] }\end{array}$ & $\begin{array}{c}\text { Wind } \\
\text { speed } \\
\text { U1(z) [m/s] }\end{array}$ & $\begin{array}{c}\text { Wind } \\
\text { speed } \\
\text { U2(z) } \\
{[\mathrm{m} / \mathrm{s}]}\end{array}$ & $\begin{array}{c}\text { Wind } \\
\text { force } \\
\text { Fwi(U1) } \\
{[\mathrm{N}]}\end{array}$ & $\begin{array}{c}\text { Wind force } \\
\text { Fwi(U2) [N] }\end{array}$ \\
\hline \hline 1 & 37.94 & 02.66 & $\begin{array}{c}\text { Rectangular cross } \\
\text { section (beam) }\end{array}$ & 2.0 & 28.2934 & 36.3772 & 37205.16 & 061502.42 \\
\hline \hline 2 & 67.86 & 14.48 & $\begin{array}{c}\text { Circular cross } \\
\text { section (cylinder) }\end{array}$ & 1.2 & 36.8748 & 47.4104 & 67820.31 & 112111.12 \\
\hline \hline 3 & 38.80 & 29.23 & Steel plate & 2.0 & 40.4322 & 51.9842 & 77700.12 & 128443.05 \\
\hline \hline 4 & 12.94 & 34.18 & Truss structure & 1.6 & 41.2245 & 53.0029 & 21551.15 & 035625.37 \\
\hline \hline 5 & 32.82 & 40.42 & $\begin{array}{c}\text { Rectangular cross } \\
\text { section (beam) }\end{array}$ & 2.0 & 42.0737 & 54.0947 & 71169.81 & 117648.06 \\
\hline \hline 6 & 15.30 & 49.52 & $\begin{array}{c}\text { Rectangular cross } \\
\text { section (beam) }\end{array}$ & 2.0 & 43.1020 & 55.4169 & 34819.54 & 057558.82 \\
\hline \hline 7 & 13.73 & 53.08 & Truss structure & 2.0 & 43.4536 & 55.8689 & 31758.40 & 052498.57 \\
\hline
\end{tabular}

wind based on Panofsky and Dutton 1984, Simiu which the wind force acts; $\mathrm{k}$ - the surface friction coefficient.

Oed on the Overview of temporary and apSFRY with a return period of 50 years [15] as well as the works [16] and [05], the reference (basic) are obtained for determining the logarithmic wind speed profile at the height $z$ in the function of two (Table 2 ):

$$
\begin{aligned}
& \mathrm{U}_{1}(\mathrm{z})=35 \cdot\left(1+\frac{1}{0.4} \sqrt{0.00335} \ln \frac{\mathrm{z}}{10}\right) \\
& \mathrm{U}_{2}(\mathrm{z})=45 \cdot\left(1+\frac{1}{0.4} \sqrt{0.00335} \ln \frac{\mathrm{z}}{10}\right)
\end{aligned}
$$


The developed finite element model of the shipyard level-luffing crane as a typical representative of the high structures was used to transient analysis where the recommended coefficient of the wind static force growth was not available. The real nature of the strong wind in the Western Balkans region, based on a multi-annual monitoring by the meteorological stations, was included in the calculation of the function of time $F h(t)$, Eq. (9). Such analyses are closer to the actual development of the situation (recurrence) in the given off-shore locations and they represent a safer guarantee for the crane owner to preserve its stability. The strong wind has a wave shape presenting a time function. Although the wind has a random character, a certain recurrence, such as the terrain directing of the air flow on the coast caused by seasonal cycles in nature and environmental, can occur. Therefore, as a general model of dynamic analysis of structures, the transient structural analysis of the effect of wind load was used. Also, the excitation forces (and speeds) were taken from the official meteorological evidence for the observed period. The authors' choice of the wave function of excitation which acts on the crane structure is an adverse wind effect with one or more short and strong harmonic gusts of the wind. The wave function which describes the dynamic character of the wind is mathematically presented in Eq. (9) as an individual force $\mathrm{Fh}$ for an individual surface $\mathrm{A}$ and angle of incidence $a$ :

$$
\mathrm{F}_{\mathrm{h}}(\mathrm{t})=\mathrm{F}_{\mathrm{W}} \cdot \mathrm{f}_{\mathrm{W}}(\mathrm{t})=\frac{1}{2} \rho \mathrm{C}_{\mathrm{S}} A v^{2} \mathrm{f}_{\mathrm{w}}(\mathrm{t}) \cos \alpha
$$

Where Fw is the steady wind force as a static effect and $f w(t)$ is the harmonic function of the wind excitation.

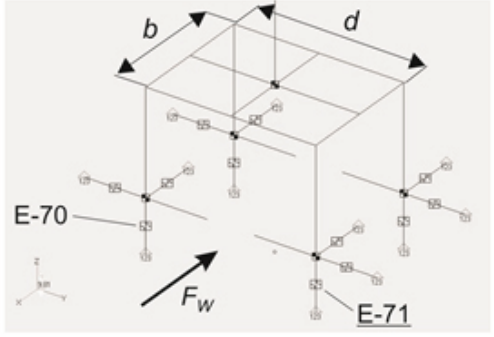

(a)

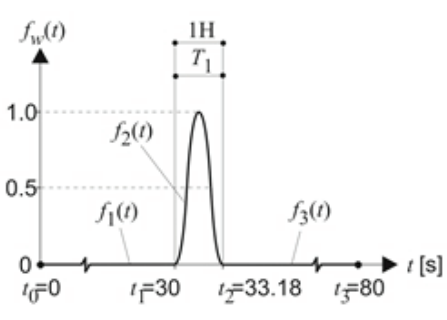

(b)

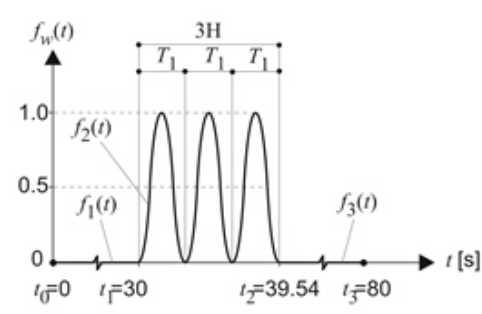

(c)

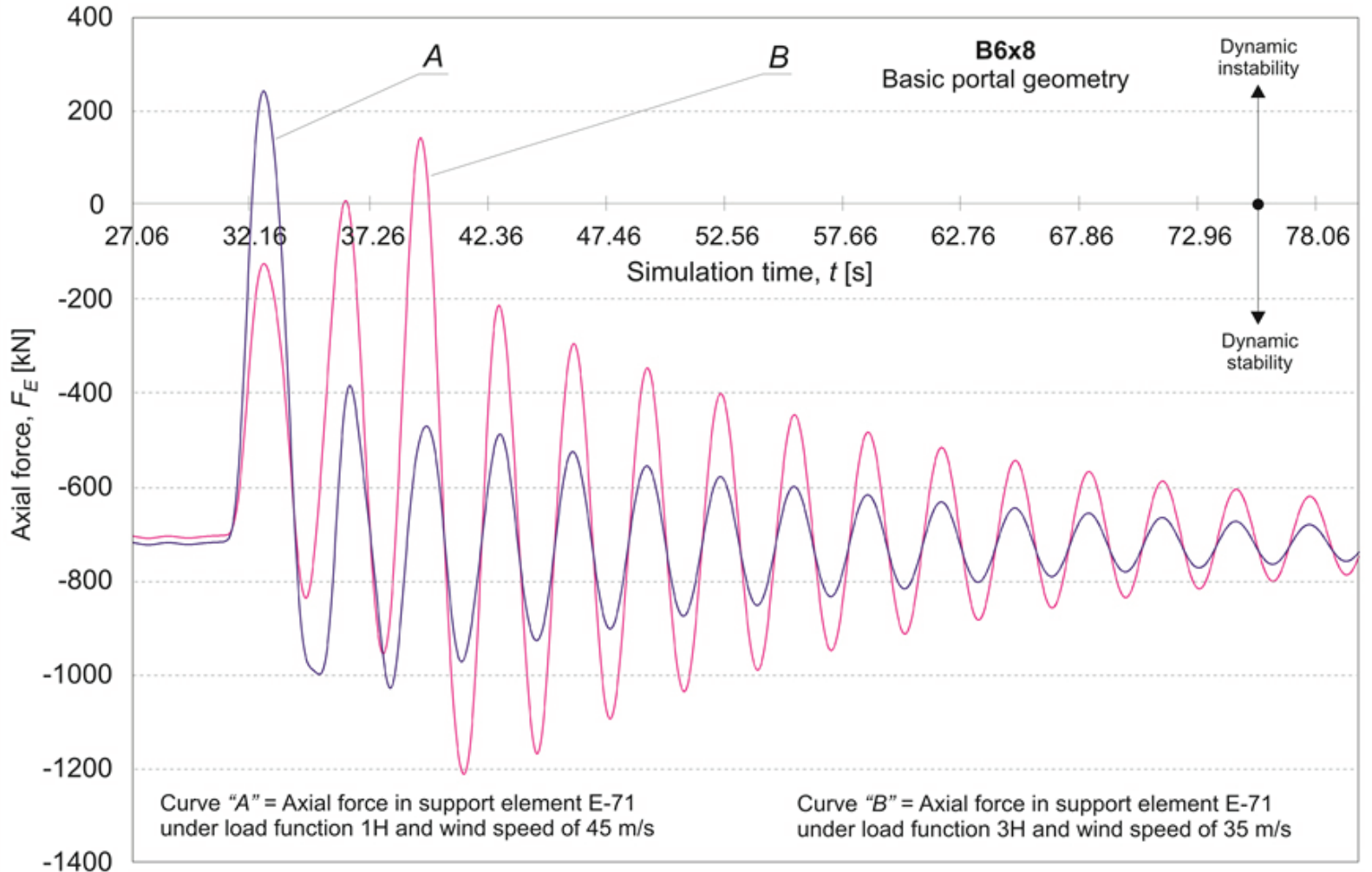

(d)

Figure 4: (a) Simplified scheme of the portal with the support elements, (b) sine excitation with one wind gust, (c) sine excitation with three wind gusts, (d) axial forces in the finite element E-71 (support) of the derived portal with basic dimensions: $b \times d=6 \times 8 \mathrm{~m}$ 
Since the wind exposed crane surface is divided into seven parts, seven discrete harmonic functions of the force can be formulated for each of these areas, Eq.(9). To observe the behaviour of the structure caused by the wind, the function of influence has to be expanded by the initial calm state due to the lack of the wind and the function of the calm state after the wind has passed. This multi-function has several parts in the total simulation time of 80 seconds. The synchronous function of the wind excitation $\mathrm{fw}(\mathrm{t})$ is composed of three interconnected elementary functions $f(t), n=1 \div 3$, Eqs. (10)-(11). In the time of simulation, the segment $t 1 \div \mathrm{t} 2$ of the excitation function $\mathrm{fw}(\mathrm{t})$ has a harmonic (sine) shape $\mathrm{f} 2(\mathrm{t})$, with one $(1 \mathrm{H}$, Fig. 4(b)) and three (3H, Figure 4(c)) wind gusts $(\mathrm{H}-$ harmonic).

$$
\begin{aligned}
& \mathrm{f}_{\mathrm{W}}(\mathrm{t})_{1 H}= \begin{cases}\mathrm{f}_{1}(\mathrm{t})=0, & \mathrm{t}=0 \div \mathrm{t}_{1}, \quad\left(\mathrm{t}_{1}=30 \mathrm{~s}\right) \\
\mathrm{f}_{2}(\mathrm{t})=\frac{1}{2}+\frac{1}{2} \sin \omega \mathrm{t}, & \mathrm{t}=\mathrm{t}_{1} \div \mathrm{t}_{2}, \quad\left(\mathrm{t}_{2}=33.18 \mathrm{~s}\right) \\
\mathrm{f}_{3}(\mathrm{t})=0, \quad \mathrm{t}=\mathrm{t}_{2} \div \mathrm{t}_{3}, \quad\left(\mathrm{t}_{3}=80 \mathrm{~s}\right)\end{cases} \\
& \mathrm{f}_{\mathrm{W}}(\mathrm{t})_{3 \mathrm{H}}= \begin{cases}\mathrm{f}_{1}(\mathrm{t})=0, \mathrm{t}=0 \div \mathrm{t}_{1}, & \left(\mathrm{t}_{1}=30 \mathrm{~s}\right) \\
\mathrm{f}_{2}(\mathrm{t})=\frac{1}{2}+\frac{1}{2} \sin \omega \mathrm{t}, & \mathrm{t}=\mathrm{t}_{1} \div \mathrm{t}_{2}, \quad\left(\mathrm{t}_{2}=39.54 \mathrm{~s}\right) \\
\mathrm{f}_{3}(\mathrm{t})=0, & \mathrm{t}=\mathrm{t}_{2} \div \mathrm{t}_{3}, \quad\left(\mathrm{t}_{3}=80 \mathrm{~s}\right)\end{cases}
\end{aligned}
$$

Such a choice of harmonic functions aims to show the importance of the retroactive effect of the wind that attacks a high structure with more gusts by causing its dynamic response. These functions have the same step, i.e. period of oscillation and a different number of wind gusts $(1 \mathrm{H}$ and $3 \mathrm{H}$ ). The effect of the modelled functions of wind on the crane causes: a) large horizontal displacements of some elements of the structure such as a rocker, b) a large increase in the reaction force of the supports important for evaluating the dynamic stability of the entire structure.

\section{ANALYSIS OF EXTREME INFLUENCE RESULTS}

Procedure: Dynamic response of the elastic supports of the crane is observed here. More precisely, the dynamic stability of the crane is observed under the strong wind influence at one gust $(1 \mathrm{H})$ and three gusts $(3 \mathrm{H})$. One gust of wind $(1 \mathrm{H})$ occurs at the reference speed $\mathrm{v}=45 \mathrm{~m} / \mathrm{s}$ while three wind gusts $(3 \mathrm{H})$ occur at the reference speed $v=35 \mathrm{~m} / \mathrm{s}$. The initial analysis was conducted on the derived crane structure solution named PULA-2 with the basic dimensions of the portal $b 1 \times d 1=6 \times 8 \mathrm{~m}$. Dimension $\mathrm{b} 1=6 \mathrm{~m}$ extends in global $x$-direction i.e. the wind direction (Fw, Fig. 1).

Procedure after redesigning: New analyses were then performed on the redesigned $\mathrm{FE}$ model of the SC with a modified portal geometry i.e. a new portal basis of dimensions: $b 2 \times d 2=8 \times 8 \mathrm{~m}$. A modal analysis aimed to determine the new lowest (resonant) eigenfrequency whose current value is $w_{1(6 \times 8)}=w_{\min (6 \times 8)}=0.3149 \mathrm{~Hz}$ was the first carried out. The transient analyses for both wind speeds and excitation forces i.e. both load types were conducted after that. For both load cases $1 \mathrm{H}$ and $3 \mathrm{H}$, the wind gust with one, Eq. (10), and three, Eq. (11), uniform impacts, and the same critical gust period $T 1=3.18 \mathrm{~s}$ is simulated after the period 0-30 s without wind (function f1(t)). Reference cases of accidents at high and heavy frame structures with resonant characteristics under the influence of natural dynamic phenomena are used in the paper to further the understanding of the unpredictable nature of strong wind. One such accident was the collapse of Falcon Crane Liverpool (39 $\mathrm{m}$ in height), [01], under the gust of wind at speed of $82 \mathrm{~km} / \mathrm{h}$ in the duration of $1 \mathrm{sec}$. The most critical case of analysis was a gust of strong wind, at the lowest eigenfrequency of vibration of the structure, that elastically moved the structure in the direction of the wind action - the observed direction (Fw) in Fig. 1. This case of load leads to resonant oscillatory behaviour of the crane. The critical i.e. lowest eigenfrequency for both cases of geometry 
of the crane portal $(\mathrm{b} 1 \times \mathrm{d} 1=6 \times 8 \mathrm{~m} ; \mathrm{b} 2 \times \mathrm{d} 2=8 \times 8 \mathrm{~m})$ was computed by modal analysis: $\mathrm{w}_{1(6 \times 8)}=\mathrm{w}_{\min (6 \times 8)}$ $(6 \times 8)=0.3147 \mathrm{~Hz}$ and $w_{1(8 \times 8)}=w_{\min (8 \times 8)}=0.3149 \mathrm{~Hz}$. The reaction forces in the supporting members $\mathrm{E}-70$ and E-71 (marked in Fig. 4(a)), as well as elements E-59 and E-60 on the opposite side of the portal (unmarked in Fig.4(a)), remained negative during the action of the static wind force. On that occasion, the members were under pressure. This response of the structure at the static load of the wind showed the sufficient static stability of the structure. The dynamic response of the crane structure was obtained by transient analysis. The analysis was carried out on a faithful structural dynamic model of the crane. The intensity of strong wind force is labelled as Fwi and excitation function is written in Eqs. (10)-(11). Parameters of numerical integration take the following values: the integration step is $0.03 \mathrm{~s}$ and the number of output sets is 2667 . The lowest eigenfrequency of the structure was taken for modelling a periodic nature of the strong wind which would be the worst case of load.

In both cases of the analysis $(1 \mathrm{H}$ and $3 \mathrm{H})$, dynamic instability of the initial crane portal of dimensions $b \times d=6 \times 8 m$ occurred sooner or later during the simulation (curve A and B, Fig. 4(d)) and thus caused the overturning of the crane. One can see from the diagram (curve B, Fig. 4(d)) that even a wind speed of less than $35 \mathrm{~m} /$ $s$ at more gusts causes almost the same effect on the structure - instability as well as the faster speed $v=45 \mathrm{~m} / \mathrm{s}$ at one gust. The change of force is shown in the diagram only for the element E-71 because it has the biggest magnitudes of forces so that this element is very sensitive to the wind action - disturbance of stability. The reference wind speeds are different because the higher speed $v=45 \mathrm{~m} / \mathrm{s}$ corresponds only to one wind gust (function $1 \mathrm{H}$ ) while the lower speed $v=35$ $\mathrm{m} / \mathrm{s}$ to three wind gusts $(3 \mathrm{H})$, which is a possible real situation in the Balkan peninsula area. The wind excitation force functions $1 \mathrm{H}$ and $3 \mathrm{H}$ are complex and have a sine shape whose step (period) corresponds to the resonant eigenfrequency $\mathrm{w}_{16 \times 8}=0.3147 \mathrm{~Hz}$ for the basic construction with the portal of dimensions $\mathrm{b} 1 \times \mathrm{d} 1=6 \times 8 \mathrm{~m}$, i.e. $w_{\min (8 \times 8)}=0.3149 \mathrm{~Hz}$ for a modified geometry of the portal $b 2 \times d 2=8 \times 8 m$ of the elastically supported crane in the direction of three global axes, Fig. 4(a). Figure 5 shows the curves $C$ and D obtained by the transient analysis of the redesigned crane structure, which represent the forces in the supports (only shown are forces in the element E-71). The magnitudes of forces are significantly reduced by redesigning so that one can talk about preserved stability in both cases of load at different speeds of an extreme airflow (if a randomly chosen extreme ambient resonance effect of the wind is acceptable).

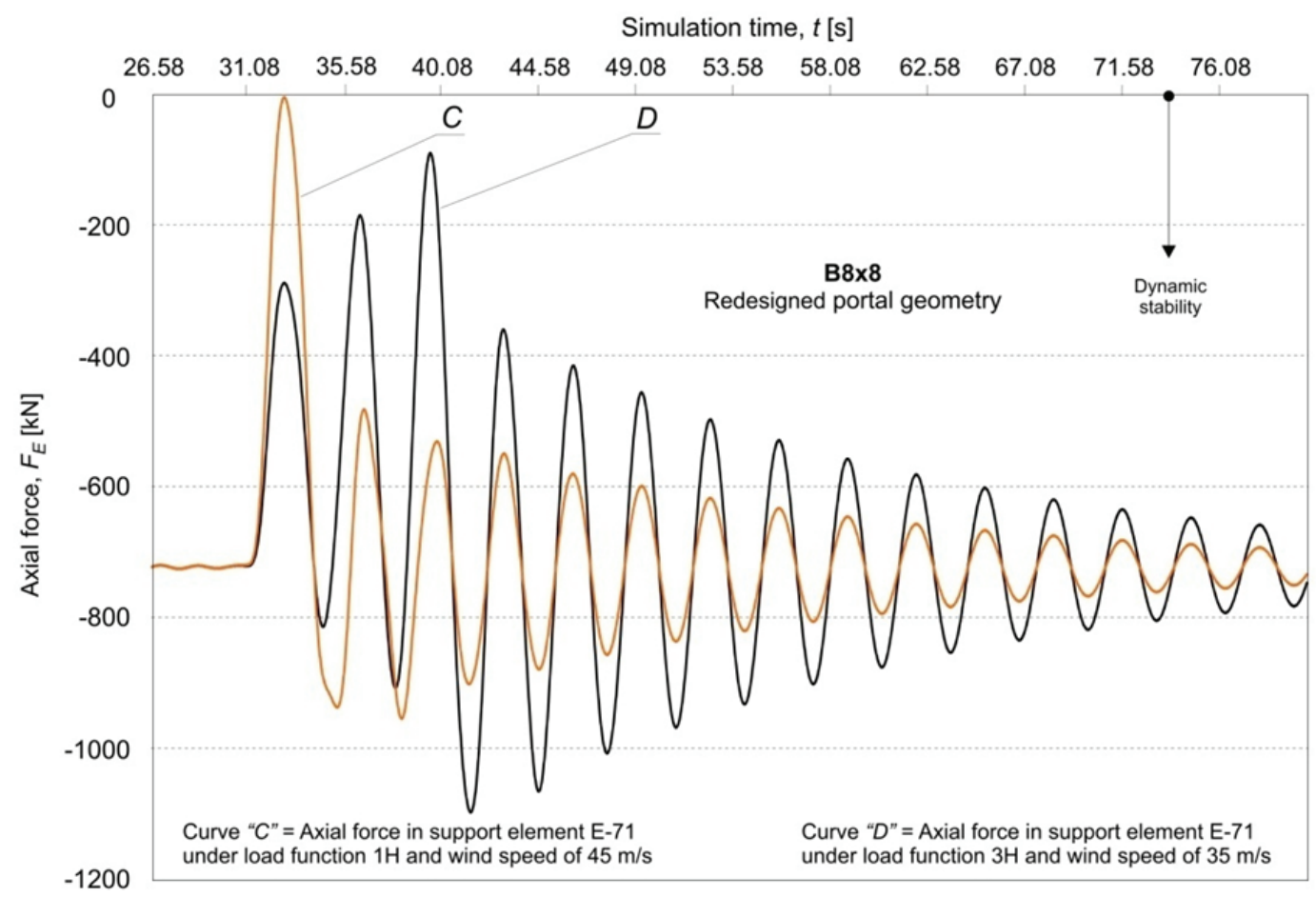

Figure 5: Reaction forces in the finite element (elastic support) E-71 of the redesigned portal with new basis $b 2 \times d 2=8 \times 8 \mathrm{~m}$ and two variable wind loads $1 \mathrm{H}$ and $3 \mathrm{H}$ (No loss of stability!) 
By comparing the results of the transient analysis under wind influence with the static analysis without wind influence, we get the quantity of dynamic coefficients Kd, Eq. (12), for the four selected finite elements in order from E-212 to E-215 which represent the portal legs, where: $\mathrm{FE}$,mindyn is the minimal dynamic pressure axial force (the biggest axial force) in the leg elements of the initial portal basis $b \times d=6 \times 8 m$ which calculated by transient analysis; FEstat is the static force in the leg elements calculated by nonlinear static analysis of the portal with the initial basis $6 \times 8 \mathrm{~m}$ (without wind influence).

$\mathrm{K}_{\mathrm{d}}=\mathrm{F}_{\mathrm{E}, \min }^{\mathrm{dyn}} / \mathrm{F}_{\mathrm{E}}^{\text {stat }}$

The elements E-212 and E-213 are placed behind the surfaces exposed to the wind effect (the wind presses them), and the elements E-214

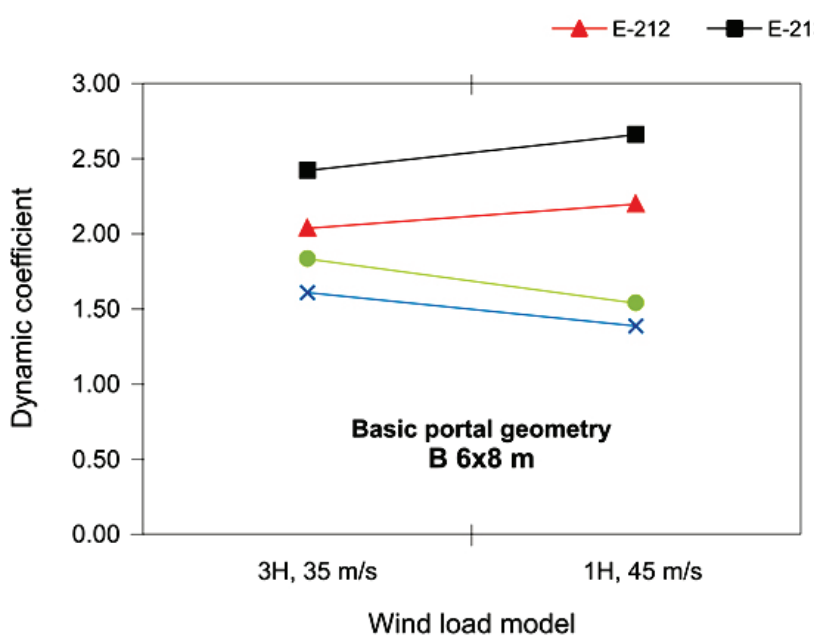

and E-215 are placed in front and directly exposed to the wind effect (they are raised under the influence of the wind). The wind models are denoted as: $3 \mathrm{H}$ at wind speed of $35 \mathrm{~m} / \mathrm{s}$, and $1 \mathrm{H}$ at speed of $45 \mathrm{~m} / \mathrm{s}$, Figure 6 . Through more case studies of wind effect on tall cranes, a better adjustment of the height, shape and basic position can be implemented. One can notice that the initial model of the portal $6 \times 8 \mathrm{~m}$ (in Figure 1 ) has a ratio of the crane height $\mathrm{H}$ and basis $\mathrm{b}$ (in fact the basis $b_{1}$ ):

$$
\frac{\mathrm{H}}{\mathrm{b}_{1}}=\frac{61.13}{6}=10.188
$$

while the redesigned model of the portal $8 \times 8 \mathrm{~m}$ (with the greater depth $b_{2}=8 \mathrm{~m}$ ) has the ratio:

$\frac{\mathrm{H}}{\mathrm{b}_{2}}=\frac{61.13}{8}=7.64$

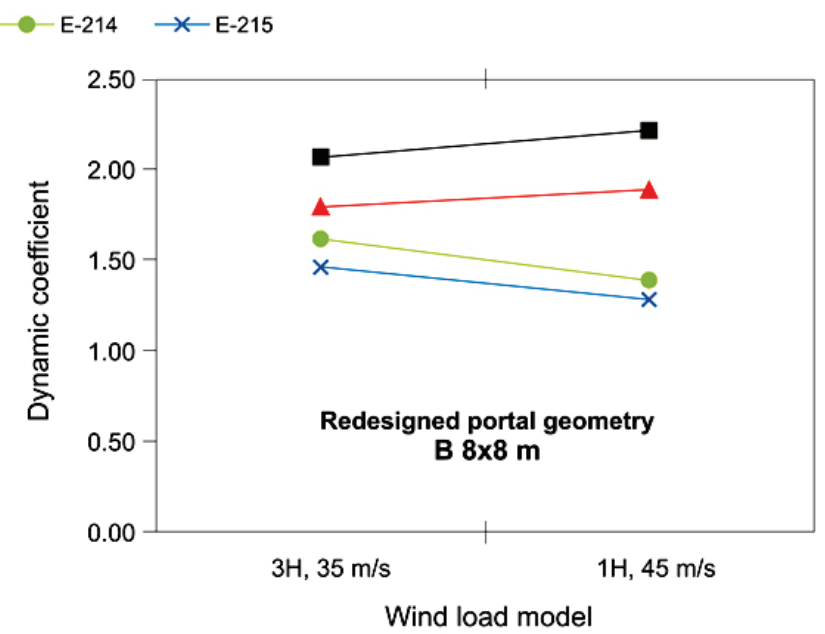

Figure 6: Structural dynamic coefficients expressed through the finite elements of the portal legs (E-212 to E-215) for: the derived (basic) portal geometry with basis $b 1 \times d 1=6 \times 8 m-$ on the left side, and the redesigned portal geometry with the new basis $b 2 \times d 2=8 \times 8 m-$ on the right side

In Fig. 5 we can see that the redesigned geometry of the crane portal $(\mathrm{H} / \mathrm{b} 2=7.64)$ provides the dynamic stability in the given wind load conditions. Otherwise, the unstable states (when lifting the legs of the portal) at the same wind effects and a smaller width $b$ of the portal $(\mathrm{H} / \mathrm{b} 1=10.188$, Fig. 4) are obtained. As a temporary criterion for portal designing, the authors recommend a "soft" criterion for the design of crane's height and portal basis in the case of tall crane structures, i.e.:

$$
\frac{\mathrm{H}}{\mathrm{b}}<7.5
$$

We can assess the success of design by using the obtained dynamic coefficients. Thus, in the observed case, we can see that the extreme wind consequently causes the dynamic coefficients above expected values. The dynamic coefficients go to $\mathrm{Kd}=2.21$ (Figure 6, for speed of $45 \mathrm{~m} / \mathrm{s}$ ) after the redesigning. It points to the need for further improvement of the portal geometry (redesign) and structural aerodynamics in order to reduce the dynamic coefficients limiting it up to 1.5 .

\section{CONCLUSION}

By these comparative analyses, the dynamic stability of a tall shipbuilding crane subjected to an extreme environmental (local) wind effect is checked. Thereby, suitability of the crane portal 
design for adverse natural wind effects is considered. The comparison was conducted by a quasi-static and transient dynamic model of the wind influence. The dynamic coefficients obtained as a consequently changed design of the basic (portal) structure of the CS are observed here. On the basis of these comparative analyses some rules can be established:

1. The best design of tall cranes implies the choice of geometry that fully corresponds to a wind load in the observed environment. This means that the starting point for the analysis is the wind effect - a realistic timetable of speeds and directions of air flow registered on the selected locality in a 50 -year period.

2. Before a structure (tall crane) is made, its design has to guarantee the checking of the dynamic influence of the wind which changes in line with the height of the exposed surface against which the wind acts with repeating impact periods. In these situations, the case study FEM transient analyses can be useful.

3. One of the most adverse random natural wind effects on tall structures is the wind gust at an oscillation period corresponding to the lowest eigenfrequency period of the structure (resonant effect).

4. Using numerical simulations, this paper shows a greater threat of the combined load of more consecutive average maximal recorded wind gusts at a resonant schedule in comparison with a short-term gust at the maximal recorded wind force.

5. The extreme dynamic coefficients caused by a resonant repetition of the wind gust are reduced by changing (increasing) the portal basis $b \times d$, as shown in the paper (Fig. 6 ).

6. Case study simulations at extreme wind effects are an important class for checking the dynamical stability of structures and they represent the highest safety guarantees for people and material goods.

7. Influence of the wind variability on different geographic areas requires individual design as anachronistic and costly category. A universal element of design can be a new parameter of the drive class of cranes - an extreme wind for which the structure is designed. Namely, it can be a standard wind speed $(\mathrm{m} / \mathrm{s})$ denoted as: Wind-30, Wind-40, Wind-50, ..., Wind-100.
8. What is gained by redesigning the global structural geometry? Answer: A decrease in the dynamic coefficients (Figure 6).

9. Simulations based on transient analyses introduce a more realistic wind influence than quasi-static analyses, which corresponds better to the requests of the modern design.

\section{REFERENCES}

1) Ristić, N. (2009), "Hazard wind influence and collapse structure", Science and Practice, University of Niš, Faculty of Civil Engineering, 178-181.

2) Hajdin, N., Zloković, Đ., Vukobratović, M. and Đorđević, V. (-), "Active structures", Proc. Conf. Mechanics, Material and Constructions, Serbian Academy of Sciences and Arts, 83(2), 419-434.

3) Bošnjak, S., Zrnić, N. and Dragović, B. (2009), "Dynamic response of mobile elevating work platform under wind excitation", Strojniški vestnik - J. Mech. Eng., 55(2), 104-113.

4) https://en.wikipedia.org/wiki/List_of_the most_intense_tropical_cyclones

5) Bajić, A. (2011), "Spatial distribution of expected wind speed maxima in the complex terrain of Croatia as a basis for wind loads calculation", Ph.D. Dissertation, University of Zagreb, Croatia.

6) Radoičić, G. and Jovanović, M. (2013), “Experimental identification of overall structural damping of system", Strojniški vestnik - J. Mech. Eng., 59(4), 260-268.

7) Jovanović, M., Radoičić, G., Petrović, G. and Marković, D. (2011), "Dynamical models quality of truss supporting structures", Facta Universitatis - Series: Mech. Eng., 9(2), 137-148.

8) Jovanović, M. (1990), "Supporting structure level luffing system and driving mechanisms resistance of portal-jib cranes optimization", Ph.D. Dissertation, University of Niš, Niš, Serbia.

9) Radoičić, G. and Jovanović, M. (2015), "Dynamic response of heavy-lifting shipyard machines to resonant environmental load conditions", Facta Universitatis - Series: Working and Living Env. Protection, 12(3), 341-358.

10) Standard Det Norske Veritas DNV-RP-C104, 2012. 
11) Standard EN 1991-1-4-2005+A1-2010.

12) Standard ISO 4354:2009, Wind actions on structures, https://www.iso.org/ standard/38882.html

13) Rama, G. (2014), "An automatized in-place analysis of a heavy lift jack-up vessel under survival conditions", Facta Universitatis - Series: Mech. Eng., 12(2), 107-121.

14) Standard Det Norske Veritas DNV-RP-205, 2005.

15) Popović, O., Bogner, M., Simonović, A. and Stupar, S. (2011), About Chimneys, ETA, Belgrade, Serbia.
16) Zarić, M. (2014), "Storm and hurricane gusts of Košava - blizzard and snowstorm in the northern and northeastern regions of Serbia", RHMZ of the Republic of Serbia, Belgrade, January-February.

Paper sent to revision: 15.01.2017.

Paper ready for publication: 20.04.2017. 